\title{
THE SOFT TISSUES OF CONODONTS
}

SMITH*, M. Paul, School of Earth Sciences, University of Birmingham, Edgbaston, Birmingham B15 2TT, UK; ALDRIDGE, Richard J., Department of Geology, University of Leicester, University Road, Leicester LE1 7RH, UK; BRIGGS, Derek E. G., Department of Geology, University of Bristol, Bristol BS8 1RJ, UK.

After well over a century of more or less committed searching for unequivocal soft tissues of conodonts, the discovery of material from three different localities has contributed invaluable anatomical information regarding the group and has permitted a new phase of paleobiological work. Although the debate concerning the phylogenetic relationships of the group shows little sign of abating, the new data have served to focus the dialectic. Few workers now dispute the chordate affinity of the conodonts but, within that framework, opinion ranges from a close relationship with cephalochordates through basal agnathans to stem-group gnathostomes. The soft tissue data will be reviewed within the context of this debate.

The anguilliform body of the Early Carboniferous Granton specimens ranges from $21-55 \mathrm{~mm}$ in preserved length. The head is characterised by a pair of lobate structures interpreted as large eyes and the feeding apparatus of conodont elements, which is located ventrally. A pair of circular structures to the posterior of the eyes may represent sensory capsules. All of the specimens are presented in lateral aspect with laterally collapsed feeding apparatuses, indicating that the animals were laterally compressed in life. Anteriorly pointing <-shaped myomeres extend for the entire length of the trunk and paired axial lines, which narrow both anteriorly and posteriorly and terminate to the posterior of the head region, are interpreted as a notochord. Two specimens show a paired structure associated with the notochord which may represent the dorsal nerve cord. The tail bears an asymmetrical ray-supported fin.

All of the Granton specimens are of ozarkodinid taxa, but two more recently discovered localities have yielded soft tissues belonging to other orders. The oldest of these is the Late Ordovician Soom Shale of southwestern Cape Province, South Africa. The single specimen is of Promissum, a balognathid (Order Prioniodontida) previously remarkable for its giant apparatus. Only the anterior $109 \mathrm{~mm}$ of the animal are preserved, but linear scaling based upon one of the Granton specimens suggests that the maximum length would have been around $400 \mathrm{~mm}$. The muscle tissues are particularly well-preserved with $5 \mu \mathrm{m}$ diameter muscle fibres consistent with the slow muscle fibres of extant agnathans. An unmineralized band $2 \mathrm{~mm}$ high is interpreted as marking the position of the notochord and an elongate black patch of structureless organic material within the trunk may represent the gut. The anteriormost tissues of the trunk are not preserved, with the exception of well-preserved eyes. These are located antero-dorsally to the feeding apparatus, as in the Granton specimens, and fibrous mineralisation associated with the eyes may represent extrinsic eye musculature.

The third locality, from the early Silurian of Waukesha, Wisconsin, is of importance because it is the only one which has yielded the soft tissues of a coniform conodont. The single specimen of Panderodus (Order Panderodontida) again preserves only the anterior part of the animal complete with its feeding apparatus. The soft tissues are very poorly preserved but do retain traces of transverse 'segmentation' at least seven somites are visible, but the spacing suggests that up to 20 could have been present in the preserved length of $16 \mathrm{~mm}$. The trunk expands rapidly behind the head, reaching a maximum preserved width of $3.5 \mathrm{~mm}$ and an extrapolated width of $5 \mathrm{~mm}$. Although the soft parts provide few data, the apparatus is very well-preserved and, together with an abundance of Panderodus fused clusters, has enabled a detailed architectural reconstruction. The apparatus of the Waukesha specimen, and that of all of the fused clusters, is dorso-ventrally collapsed. This implies that the animal too was dorso-ventrally flattened, and therefore of radically different overall plan to the Granton and Soom specimens.

The available data from the three localities to have yielded conodont soft tissues are consistent with a phylogenetic position within the pre-gnathostome vertebrates. A large number of characters (for example eyes, the anterior termination of the notochord and the asymmetrical ray-supported tail) are more derived than those of cephalochordates and a close relationship with that group can be confidently excluded. 